\title{
Built environment impacts on walking for transport in Brisbane, Australia
}

Md. Kamruzzaman ${ }^{\mathrm{a}}{ }^{\text {, }}$, Simon Washington ${ }^{\mathrm{a}}$, Douglas Baker ${ }^{\mathrm{a}}$, Wendy Brown ${ }^{\mathrm{b}}$, Billie GilesCorti $^{\mathrm{c}}$, Gavin Turrell

${ }^{a}$ School of Civil Engineering and the Built Environment, Queensland University of Technology, 2 George Street, Brisbane, Queensland 4000, Australia.

${ }^{\mathrm{b}}$ School of Human Movement Studies, University of Queensland, Blair Drive, St Lucia, Queensland 4072, Australia

${ }^{\mathrm{C}}$ McCaughey Centre, VicHealth Centre for Community Wellbeing, Melbourne School of Population Health, University of Melbourne, Melbourne Victoria 3010, Australia.

d School of Public Health and Social Work, Queensland University of Technology, Victoria Park Road, Kelvin Grove, Brisbane, Queensland 4059, Australia.

\section{Abstract}

This study examines the association between urban form and walking for transport in Brisbane, Australia based on both panel and cross-sectional data. Cross-sectional data are used to determine whether urban form was associated with walking for transport in 2011. Panel data are used to evaluate whether changes in the built environment altered walking behaviour between 2009 and 2011. Results from the cross-sectional data suggest that individuals are significantly more likely to be walkers if they live in an area with a wellconnected street network and an accessible train station. The longitudinal analysis confirms these relationships; there also was however, a significant impact of travel attitudes and perceptions on walking behaviour. The findings suggest that the built environment continues to be an important factor to encourage walking; however, interventions are also required to change social norms in order to increase the receptiveness for and participation in walking.

Keywords: urban form; residential self-selection; walking for transport; travel attitudes.

\footnotetext{
${ }^{1}$ Corresponding author. Tel.: +61 (0)7 3138 2510; fax: +61 (0)7 3138 1170. E-mail addresses: md.kamruzzaman@qut.edu.au (Md. Kamruzzaman), simon.washington@qut.edu.au (Simon Washington), d2.baker@qut.edu.au (Douglas Baker), wbrown@hms.uq.edu.au (Wendy Brown), b.giles-corti@unimelb.edu.au (Billie Giles-Corti), g.turrell@qut.edu.au (Gavin Turrell).
} 


\section{Introduction}

There is now a well-established link between urban form (residential density, land use diversity, street connectivity, access to public transport) and walking for transport (Frank et al. 2005; Saelens et al. 2003; Van Cauwenberg et al. 2011); and the adoption of policies to encourage these urban form characteristics has been recommended as a means to enhance walking (Guo and Chen 2007). Most research to date is, however, based on cross-sectional evidence, and the potential for spurious relationship remains an issue. Hence, causal links between land use policy and active travel cannot be inferred (Mokhtarian and Cao 2008). As a result, Krizek et al. (2009) caution not to overestimate the benefits of changes to urban form to increase active travel.

Four criteria are used to establish causal inferences: a) associations - a statistically significant relationship between the cause and effect; b) non-spuriousness - a relationship that cannot be attributed to another variable i.e. no third factor creates an accidental relationship between the variables; c) time precedence/order - the cause precedes the effect; and d) causal mechanisms - a plausible explanation for why the alleged cause should produce the observed effect (Singleton and Straits 1999). Much of the prior research examining associations between urban form and active transport has satisfied only the first and fourth criteria using non-experimental cross sectional research designs. Recently, several studies have tested this link by focusing on the non-spuriousness criterion by controlling for residential self-selection effects (see, Guo 2009; Mokhtarian and Cao 2008 for a review). However, most of these studies have not taken into account the 'time precedence' criterion, due to the cross-sectional nature of the data.

Although travel behaviour data both before and after interventions ('treatments') are necessary to truly understand the impact of environmental interventions on travel behaviour, such datasets are rarely available in transport research (Handy et al. 2005). As a surrogate measure, researchers sometime use travel behaviour data of individuals who have changed residential locations. Residential relocation acts as an intervention in these studies, whereby 
pre- and post-move travel behaviour and urban form data are compared to assess causality. A cautious argument put forward in these studies is that the self-selection effects are controlled because data are collected from the same person over two different time periods, and thus any behavioural changes are due to changes in urban form. However, a problem with this longitudinal approach is that "the relocating households are themselves a selfselected group" (Bhat and Guo 2007, p.511), and evidence shows that households might move due to dissonance in the pre-move neighbourhood (Kamruzzaman et al. 2013b). In addition, research aimed at validating the causality between urban form and travel behaviour originates largely from the USA; with a few examples from Europe (e.g. Aditjandra et al. 2012) and Australia (e.g. Giles-Corti et al. 2013). This lack of geographical diversity, therefore, limits the external validity and generalisation of the results. Finally, the results reported across different studies are inconclusive and sometimes conflicting (see, Bagley and Mokhtarian 2002; Lee et al. 2009).

The objective of this research is twofold: first, we examine the relationship between urban form and time spent (minutes) walking for transport in Brisbane, Australia, using both crosssectional and longitudinal research design frameworks. Second, we investigate whether the results from cross-sectional data are similar to those from longitudinal data, to inform the question of whether the former can effectively be used in the absence of rarely available longitudinal data in transport research. A further contribution of this research is the utilisation of a new dataset, with potential to examine the effects of changes in the environment as 'natural interventions,' an approach which offers an opportunity to rigorously examine the hypothesised relationships. The literature on the links between urban form and travel behaviour is reviewed in Section 2. Data and methods used to examine the research aims are discussed in Section 3, the results of the analyses are presented in Section 4, and the conclusions are provided in Section 5. 


\section{Literature review}

\subsection{Urban form and walking for transport: causal mechanism}

Different characteristics of the built environment have been tested, and despite operational differences, the factors that are consistently identified as having a positive association with walking for transport include higher residential density, diverse land uses, well connected street networks, and accessible public transport (PT) (Frank et al. 2005). A mix of different land uses (residential, commercial, recreational, and institutional) facilitates participation in local activities, and therefore, reduces the need for motorised travel to participate in distant activities (Kamruzzaman et al. 2014). An area where diverse land uses exist typically offers more non-residential destinations (including public transport) for walking journeys, and thus may facilitate more transport-related walking (Duncan et al. 2010). Higher residential densities are more likely to support the presence of shops and services; thus the density of an area is also indirectly related to walking (Transportation Research Board 2005). Density is also thought to be important because higher densities tend to create a critical mass of people - more people to walk, to see others walking, and to feel safer. Traffic congestion also increases with population and employment density so that at a certain threshold it is more convenient to walk (Oakes et al. 2007). Street pattern or connectivity affects the directness of travel and proximity of destinations, making travel more efficient, and the number of alternative routes with implications for interest and safety (Oakes et al. 2007). Walking for transport is encouraged when the street network is more connected, obstacles are kept to a minimum, and no need to cross major roads (Saelens et al. 2003).

\subsection{Urban form and walking for transport: a spurious relationship?}

Despite consistent cross sectional evidence of associations between the above environmental factors and travel behaviour, the causality of these factors is as yet not clear (Mokhtarian and Cao 2008). Handy and Clifton (2001) highlighted that the relationship between urban form and travel behaviour could be capturing residential self-selection effects i.e., an individual's inclination to choose a particular neighbourhood according to their current 
travel abilities, needs, and preferences rather than neighbourhood factors changing behaviour (Guo and Chen 2007; Pinjari et al. 2007). Two sources of residential self-selection are socio-demographics (e.g. car ownership), and travel attitudes and perceptions (Mokhtarian and Cao 2008). Commonly identified attitudinal and/or perceptual factors included environmental concerns, car affection, perception of crash risk, ecological norm (e.g. obligation), beliefs about a mode's ability of meeting one's needs, and habits (Cools et al. 2009; Elias and Shiftan 2012; Manaugh and El-Geneidy 2013; Matthies et al. 2002; Thøgersen 2006). Few studies have collected residential preference data directly from study participants to control for residential self-selection effect (Giles-Corti et al. 2013; Handy et al. 2006; Manaugh and El-Geneidy 2013). Generally, researchers used two broad approaches differentiated by analyses of cross-sectional and longitudinal data to assess causality of the built environment in changing travel behaviour.

\subsection{Cross-sectional studies}

Researchers have approached the problem of establishing causality with only crosssectional data using matched attitudes, instrumental variables model (IVM), joint-choice model, structural equation modelling (SEM), and path choice modelling (Mokhtarian and Cao 2008). Schwanen and Mokhtarian (2005a, b) applied a matched attitudes method and found that the built environment had a strong influence on commuting mode choice and travel distances in the San Francisco Bay Area. Similarly, Guo (2009) has shown that the quality of the pedestrian environment determines commuters' (who arguably shared matched attitudes) egress path choice from subway station in downtown Boston. However, matched attitudes studies in other contexts (Belgium, Australia) found that mode choice was primarily determined by attitudes, and to a limited degree by the built environment (De Vos et al. 2012; Kamruzzaman et al. 2013a). These findings are similar to Bagley and Mokhtarian (2002) by estimating a SEM and found that attitudinal and lifestyle variables had the greatest impact on behaviour, whereas the built environment had little impact in San Francisco. The evidence of causality is not conclusive in studies that used IVM, in some cases it is verified (Khattak and Rodriguez 2005; Vance and Hedel 2007), and others causality has been 
questioned (Boarnet and Sarmiento 1998). Causality has also been reported to be scale dependent (exists at the neighbourhood level but not at the zip code level) in a case of walking trips in Portland (Greenwald and Boarnet 2001).

Similar to causality, the impacts of self-selection on travel behaviour also vary between studies. For example, using a joint-choice model of residential location and rail commuting, Cervero and Duncan (2008) found that residential self-selection explained a higher (40\%) level of rail commute decision. On the other hand, using the same data set, Bhat and Guo (2007) did not find an association between self-selection of neighbourhoods and the level of car-ownership in the San Francisco Bay Area. Again, using the same datasets, Pinjari et al. (2007) jointly examined residential location choice and commuter mode choice behaviour and reported that both built environmental attributes and residential self-selection have significant impacts on commute mode choice. A similar finding was reported in a joint-choice analysis of residential location and car ownership in New York (Salon 2009).

In summary, the effects of both urban form and residential self-selection vary depending on the type of indicator used to analyse travel behaviour. In some cases, the effects of urban form are greater than residential self-selection effects, whereas other studies have found the opposite. Only a few studies have not found any significant impact of these variables suggesting the importance of including both types of variables in assessing causality.

\subsection{Longitudinal studies}

Cross-sectional data are sufficient for establishing evidence for association and nonspuriousness, but inadequate for establishing a time precedence necessary to argue for a causal relationship (Handy et al. 2005). A stronger test of a causal relationship is achieved through an examination of the association between a change in the built environment and a change in travel behaviour. If a change in the built environment precedes the change in travel behaviour, then a causal relationship is more likely (Handy et al. 2005; Leslie et al. 2005; Singleton and Straits 1999). 
Handy et al. (2005) and (2006) used quasi-longitudinal data and measured changes in travel behaviour, built environment, and car-ownership levels of individuals living in San Francisco. Using an ordered probit model, the researchers concluded that there was a causal link between the built environment and driving behaviour, and between the built environment and walking behaviour respectively, by controlling for socio-demographic changes and postmove travel attitudes. One limitation of quasi-longitudinal studies includes recall bias (Mokhtarian and Cao 2008). Also, travel attitudes were considered to be constant across observed time period in the above studies. To overcome this limitation, Handy et al. (2005) highlighted the need for a panel survey data approach that includes both attitudinal as well as more precise measures of behavioural change. In addition, Handy et al. $(2005,2006)$ examined causal links in a unidirectional way 'from the built environment to travel behaviour'. Cao et al. (2007) and Aditjandra et al. (2012) applied SEM to examine whether multiple causal relationships exist and concluded that neighbourhood characteristics influence travel behaviour after controlling for self-selection.

Several studies have used longitudinal data and investigated travel behaviour changes before and after residential relocation. Krizek (2003) measured changes in the built environment and found that individuals relocating to areas with higher neighbourhood accessibility decreased VMT; the study did not find a causal relationship between changes in built environment and walking behaviour. The weakness of this study was a failure to account for non-movers as a control group. In contrast, Meurs and Haaijer (2001) analysed travel behaviour of movers and non-movers in the Netherlands and found evidence of causality between the characteristics of built environment and number of car trips. Both studies assumed that travel attitudes remained constant over time, given that data were collected from the same person across both time periods. However, this was found not to be true in a recent study conducted by Giles-Corti et al (2013) in Perth. 


\section{Data and methods}

\subsection{Study area}

This research was conducted in Brisbane, Queensland, Australia where a comprehensive approach has been taken to facilitate the use of active transport at all levels of planning including the state, regional and local levels (Brisbane City Council 2008; Queensland Government 2008, 2009b). Under this broader policy guidance, specific active transport plans have been formulated and directed at different spatial scales, for example, the regional 'Action Plan for Walking 2008-2010' (Queensland Government 2009a) and the local ‘Brisbane Active Transport Strategy: Walking and Cycling Plan 2005-2010’ (Brisbane City Council 2005). Various strategies are being implemented at all levels in order to achieve a $12 \%$ walking mode share (Brisbane City Council 2005). Given the policy attention walking has received in Brisbane and elsewhere (USA), this research is timely and relevant.

\subsection{Data}

Data were collected in three phases $(2007,2009$, and 2011) from 11036, 7867, and 6901 adults respectively (aged between 40 and 70 years) living in 200 census collection districts (CCDs) in Brisbane as a part of the larger HABITAT (How Areas in Brisbane Influence HealTh and AcTivity) study. A multi-stage probability sampling design was used: first, the 200 CCDs were randomly selected (Figure 1); and second, from within each CCD, a simple random sample was drawn. This research analysed data collected from the 2009 and 2011 surveys. The 2007 survey data were excluded from this analysis because questions related to travel attitudes and preferences were introduced first in the 2009 survey. Only common participants in both periods and who remained at their current address throughout the surveys were retained in the analysis. The responses in both periods were checked for consistency and completeness; and cases with missing data in any periods were excluded from further analysis in order maintain longitudinal consistency. This culling resulted in a sample size of 3708 individuals. 


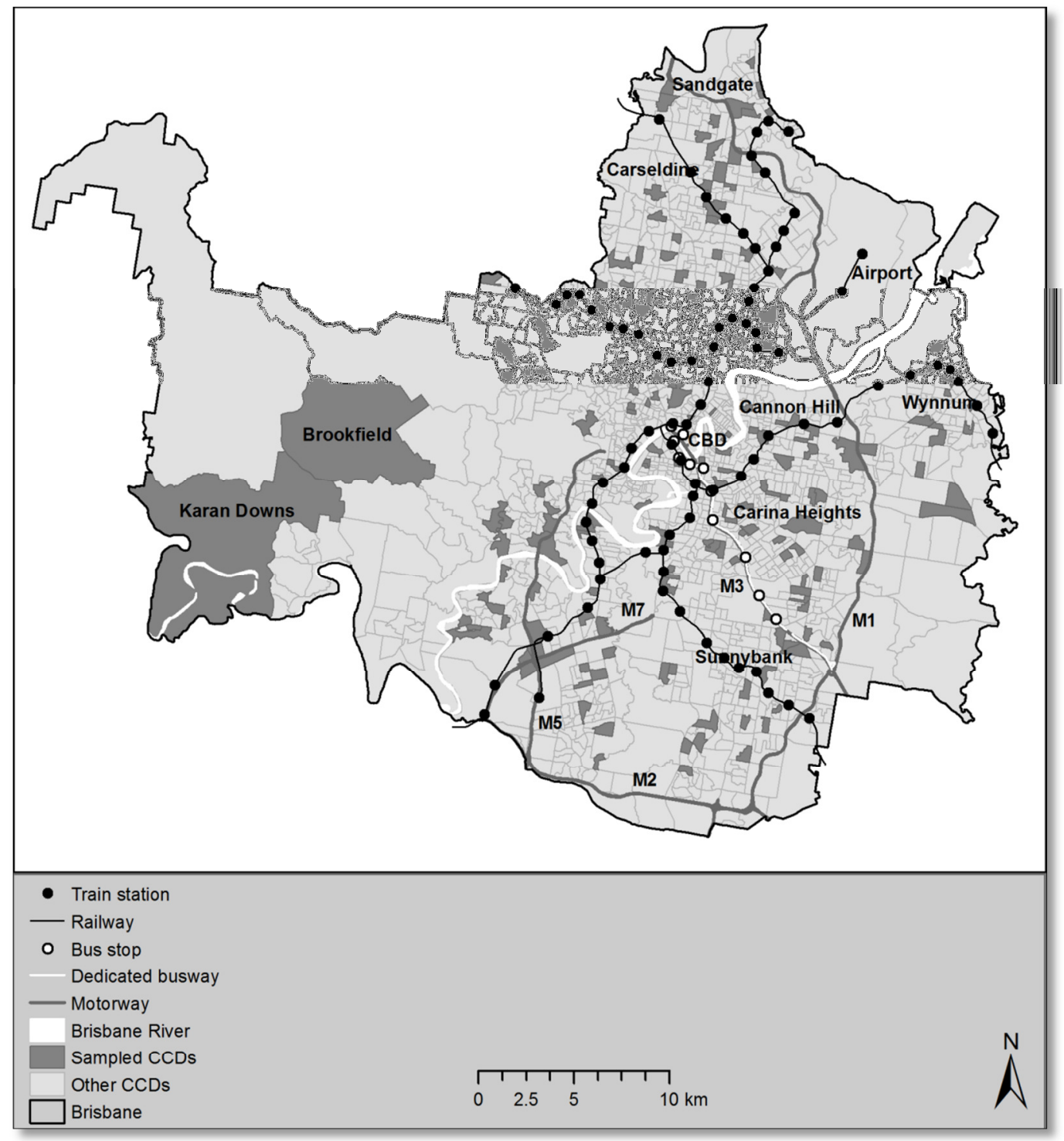

Figure 1: Sampled CCDs are distributed across Brisbane Local Government Area

\subsubsection{Dependent variables}

Neighbourhood walking has typically been classified into one of three groups including walking for exercise, walking for pleasure, and walking for transport (walking to fulfil a travel purpose such as work, shopping, etc.) (Humpel et al. 2004). This paper used data on time spent walking for transport as the dependent variable. Respondents were asked to answer the following question: "what do you estimate was the total time that you spent walking for transport in the last week?" in both periods. They were also asked not to consider walking for exercise or recreation in answering this question. This request helped to eliminate any misunderstanding that otherwise might have existed in reporting walking for transport data. The questions were adapted from the International Physical Activity Questionnaire (IPAQ) 
and their reliability and validity has been tested elsewhere (Craig et al. 2003) and in this study. The research used the 2011 walking time data for cross-sectional analysis whereas changes in walking time between 2009 and 2011 were used to assess relationships longitudinally. Changes were derived by subtracting the 2009 levels from the 2011 levelsyielding positive differences for increased walking over time. The data were examined for outlier and leverage and these were removed from further analysis using Cook's distance criteria (UCLA: Academic Technology Services 2012). This removal of outliers resulted in an analytical sample of data from 3612 individuals available for analysis. Although the reduction in sample size is at risk of biasing the sample, a comparative assessment of the sample characteristics in these periods with the complete baseline survey data showed that the samples are in general agreement.

\subsubsection{Socio-demographic characteristics}

Based on findings reported in previous studies, eight socio-demographic variables were selected for analyses: gender, age, availability of car, employment status, household size, health status, education, and country of birth (see, Cerin et al. 2009). Although respondents' income was considered for inclusion, an initial check showed that many of the respondents were reluctant to report their income levels. To test the impact of income, models were estimated using a subset with complete income data and compared to models without income and the results had not income effect —and as such an analysis without income is warranted, with the aim to exploit a relatively larger sample size. Note also that prior studies in this context found no income effect on walking behaviour (Leslie et al. 2007b), perhaps due to strong collinearity between car-ownership and income in Australian cities. Table 1 shows descriptive statistics for the socio-demographics of respondents. As suggested in the literature (Meurs and Haaijer 2001), changes in socio-demographic status of the respondents were considered for longitudinal analysis (Table 1). Gender, educational qualifications, and country of birth data were collected only once and are assumed to be static. Since all individuals experienced identical changes in age it was not considered. 
Health status of individuals was collected on a 5-point Likert scale from excellent (1) to poor (5), which was subsequently inverted to indicate that a higher score represents better health.

\begin{tabular}{|c|c|c|c|c|c|c|c|}
\hline \multirow[t]{2}{*}{ Socio-demographics } & \multicolumn{2}{|r|}{2009} & \multicolumn{2}{|r|}{2011} & \multicolumn{3}{|c|}{ Changes between 2009 and 2011} \\
\hline & Frequency & $\%$ & Frequency & $\%$ & & Frequency & $\%$ \\
\hline \multicolumn{8}{|l|}{ Gender } \\
\hline Male & 1560 & 43.2 & 1560 & 43.2 & & & \\
\hline Female & 2052 & 56.8 & 2052 & 56.8 & & & \\
\hline \multicolumn{8}{|l|}{ Car Availability } \\
\hline Yes, always & 3283 & 90.9 & 3274 & 90.6 & Unchanged & 3353 & 92.8 \\
\hline Yes, sometimes & 199 & 5.5 & 177 & 4.9 & Availability increased & 119 & 3.3 \\
\hline No & 57 & 1.6 & 75 & 2.1 & Availability decreased & 140 & 3.9 \\
\hline Do not drive & 73 & 2.0 & 86 & 2.4 & & & \\
\hline \multicolumn{8}{|l|}{ Level of education } \\
\hline Up to year 12 & 1307 & 36.2 & 1307 & 36.2 & & & \\
\hline Diploma/certificates & 1055 & 29.2 & 1055 & 29.2 & & & \\
\hline Graduate and above & 1250 & 34.6 & 1250 & 34.6 & & & \\
\hline \multicolumn{8}{|l|}{ Employment status } \\
\hline Not working & 900 & 24.9 & 1045 & 28.9 & Unchanged & 2990 & 82.8 \\
\hline Working part time & 853 & 23.6 & 840 & 23.3 & Work time increased & 226 & 6.3 \\
\hline Working full time & 1859 & 51.5 & 1727 & 47.8 & Work time decreased & 396 & 11.0 \\
\hline \multicolumn{8}{|l|}{ Country of birth } \\
\hline Australia & 2793 & 77.3 & 2793 & 77.3 & & & \\
\hline Other & 819 & 22.7 & 819 & 22.7 & & & \\
\hline Household size & Avg. 2.78 & SD. 1.35 & Avg. 2.69 & SD. 1.30 & Average change & -0.09 & SD 0.71 \\
\hline Average health status & Avg. 3.35 & SD. 0.90 & Avg. 3.36 & SD. 0.90 & Average change & 0.01 & SD 0.72 \\
\hline Average age & Avg. 54.36 & SD. 7.06 & Avg. 56.36 & SD. 7.05 & & & \\
\hline $\mathrm{N}$ & & & & & & & 3612 \\
\hline
\end{tabular}

\subsubsection{Derivation of urban form variables}

Four urban form variables (residential density, street connectivity, land use diversity, and access to PT) were derived for each individual separately for 2009 and 2011 based on a $1 \mathrm{~km}$ circular buffer from their home (Frank et al. 2005; Lee and Moudon 2006). A $1 \mathrm{~km}$ buffer has also been used to define a neighbourhood in Brisbane (Kamruzzaman et al. 2013b). Residential density was measured using the number of dwelling units located within a unit area of residential zoned land of the buffer (dwellings/hectare) (Frank et al. 2005). The 2006 and 2011 census data were used to count the number of dwellings in 2009 and 2011 respectively. All spatial data used in respective years were collected from Brisbane City Council as a part of the HABITAT study. Land use diversity was derived by quantifying the proportion of land area within the buffer that was zoned residential, commercial, industrial, recreational, and other. Using an entropy equation described by Leslie et al (2007a) the five types of land use were combined to form a measure that ranged from 0 to 1 , with 0 representing complete homogeneity of land use within the buffer, and 1 representing an even distribution of the five types of land use. Street connectivity was measured using the 
intersection density indicator based on the number of three or more way intersections located within the buffer (Stangl and Guinn 2011). Public transport accessibility was measured using perceived walking times to bus stops and train stations. Respondents were asked to indicate the time taken to reach the nearest bus stop and train station from their home on a 5-point scale $(1-5,6-10,11-20,21-30$, and more than 30 minutes $)$. These responses were recoded into binary form, indicating whether PT is accessible or not. If a bus or train service was located within a 10 minute walk of a respondent's home, then these were considered accessible. Using a ten minute walking distance has been reported as a walkable distance in Queensland and elsewhere (Ramon 2010; Smith and Taylor 1994).

\begin{tabular}{|c|c|c|c|c|c|c|}
\hline \multirow[t]{2}{*}{ Urban form variables } & \multicolumn{2}{|c|}{ Average scores } & \multicolumn{2}{|r|}{ Test results } & \multicolumn{2}{|c|}{ Changes (2009-2011) } \\
\hline & 2009 & 2011 & $t$ & $\begin{array}{r}\text { Related-samples McNemar } \\
\text { change test statistics }\end{array}$ & Frequency & $\%$ \\
\hline Residential density (dwellings/hectare) & 10.45 & 13.93 & $59.44^{\mathrm{a}}$ & & & \\
\hline Residential density unchanged & & & & & 5 & 0.1 \\
\hline Residential density increased & & & & & 3211 & 88.9 \\
\hline Residential density decreased & & & & & 396 & 11.0 \\
\hline Land use diversity & 0.60 & 0.58 & $14.18^{\mathrm{a}}$ & & & \\
\hline Land use diversity unchanged & & & & & 923 & 25.6 \\
\hline Land use diversity increased & & & & & 970 & 26.9 \\
\hline Land use diversity decreased & & & & & 1719 & 47.5 \\
\hline Number of 3-way intersections & 116.05 & 120.52 & $61.37^{\mathrm{a}}$ & & & \\
\hline Intersection unchanged & & & & & 471 & 13.1 \\
\hline Intersection increased & & & & & 3131 & 86.7 \\
\hline Intersection decreased & & & & & 10 & 0.2 \\
\hline$\%$ having access to buses & 90.8 & 91.0 & & 0.18 & & \\
\hline Access to buses improved & & & & & 137 & 3.8 \\
\hline Access to buses worsened & & & & & 129 & 3.6 \\
\hline$\%$ having access to trains & 16.4 & 16.7 & & 0.25 & & \\
\hline Access to trains improved & & & & & 103 & 2.9 \\
\hline Access to trains worsened & & & & & 95 & 2.6 \\
\hline $\mathrm{N}$ & & & & & & 3612 \\
\hline
\end{tabular}

A paired sample $t$ test was conducted using the scores associated with the three continuous urban form variables (density, diversity, and connectivity), and showed a significant difference for all three variables between the time periods for the overall sample (Table 2). These differences, therefore, provide a preliminary indication that the samples were subjected to environmental interventions between the periods. Figure 2 shows indicative changes in these built environment indicators within a neighbourhood between 2009 and 2011 (prepared using satellite images from NearMap). Regarding the perceived access time to PT services, the McNemar chi-square test shows non-significant differences between the time periods for the aggregated sample. However, more detailed analysis shows that the 
perceived access to bus and train improved for $3.8 \%$ and $2.9 \%$ of individuals respectively, and worsened for $3.6 \%$ and $2.6 \%$ individuals respectively; thus small numbers of respondents experienced changes in perceived access to PT services between time periods.
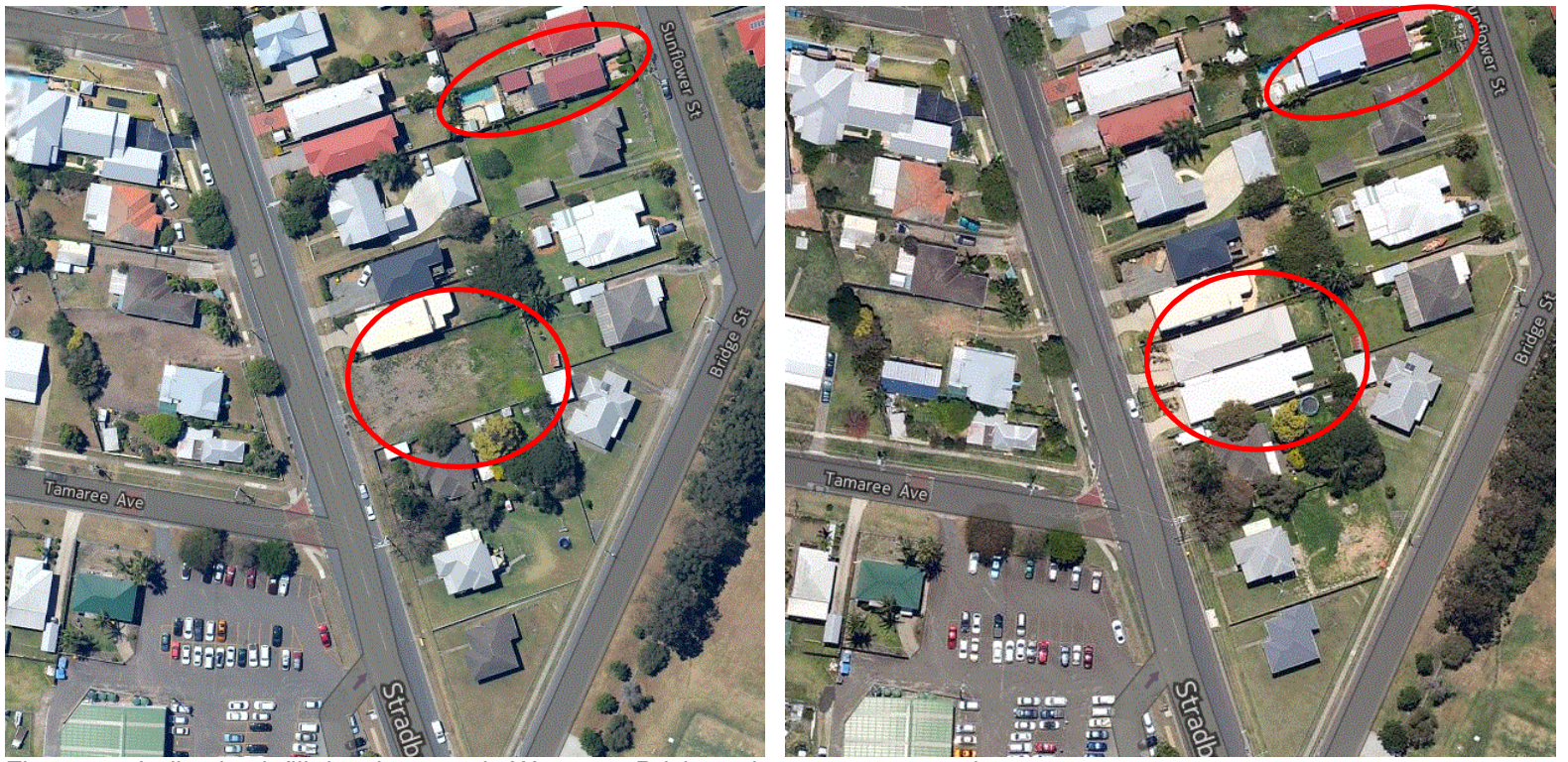

Figure 2a: Indicative infill development in Wynnum, Brisbane between 2009 and 2011
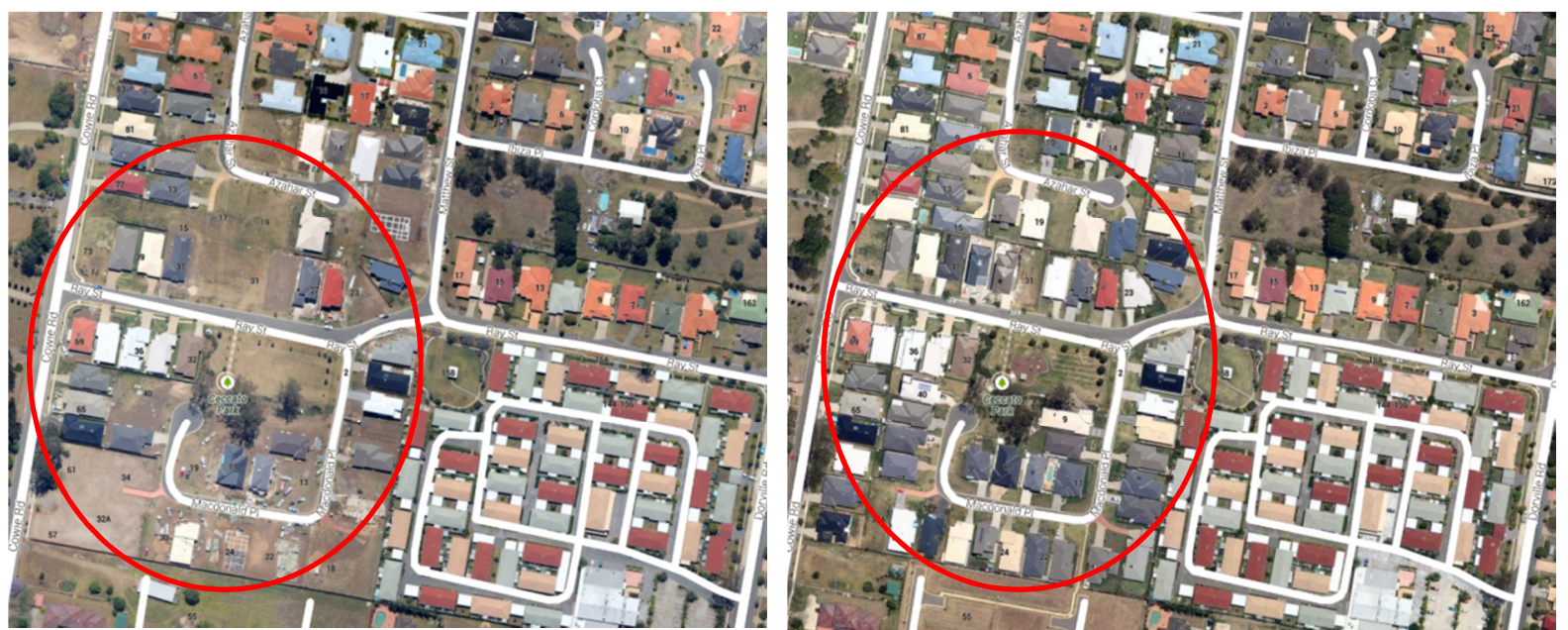

Figure 2b: Indicative new subdivision of residential zoned lands in Carseldine, Brisbane between 2009 and 2011
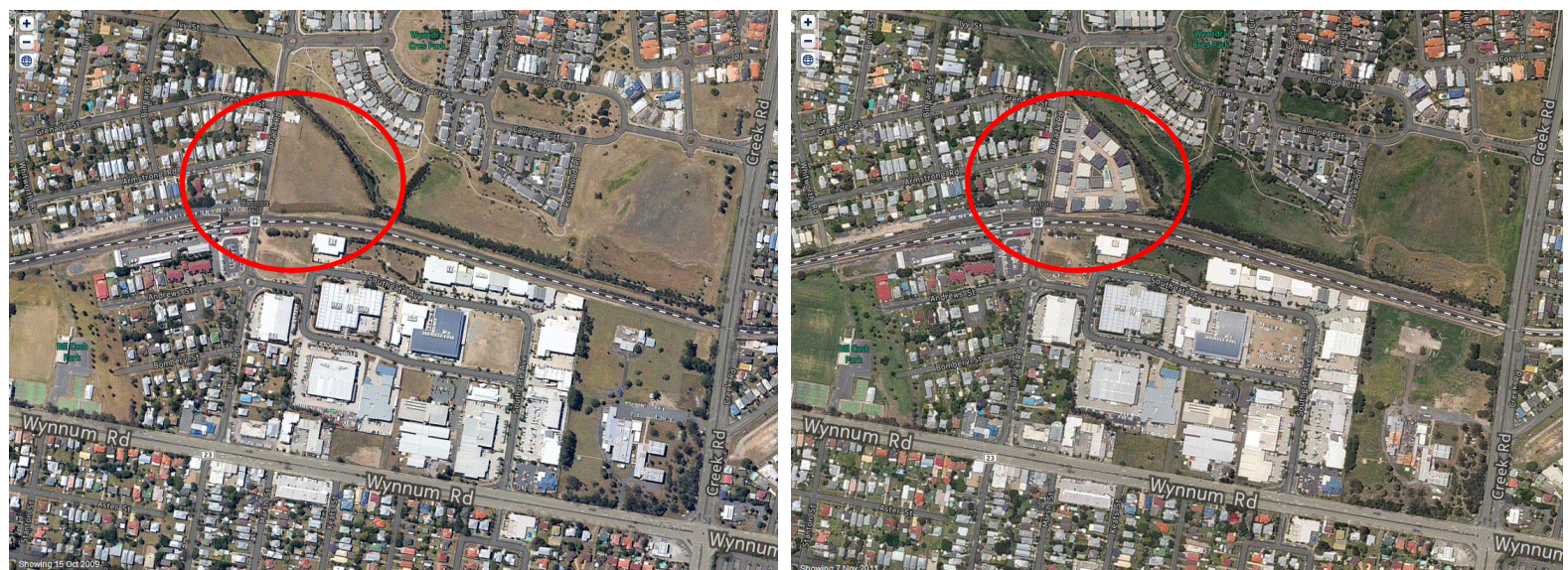

Figure 2c: Indicative new commercial development and connected road networks in Cannon Hills between 2009 and 2011 


\subsubsection{Derivation of travel attitudes and perceptions}

Data related to travel attitudes and perceptions were collected by asking respondents to indicate whether they agreed or disagreed on 16 items on a 5-point Likert scale (1 - strongly disagree to 5 - strongly agree). Based on the scores of their responses, factor analysis was conducted in order to extract the fundamental dimensions spanned by these 16 items using the principle axis factoring with oblique rotation method (Cao et al. 2007; Handy et al. 2005, 2006). Initial results from both periods showed that four statements had very low communalities and complex structure in the extracted factors (traffic congestion is a problem in Brisbane, car is safer than riding a bike, a car is expensive, and public transport is expensive). These statements were excluded and the factor analysis was re-run, resulting in none of the remaining statements with low communality or complex structures. The factor analysis generated four factor solutions in both time periods (Table 3) which explained about $52 \%$ of the variance in the data - a level considered to be defensible in the literature (Kamruzzaman and Hine 2011).

The four factors are interpreted to capture respondents' perceptions about PT, sensitivity to environmental externalities, car dependency, and safety of car travel. Similar factors have been identified in prior research (De Vos et al. 2012; Handy et al. 2005). Table 3 indicates that the overall patterns of travel attitudes and perceptions remain unchanged between the periods for the aggregate sample. However, travel pattern changes may emerge at the individual level - so attitudinal changes were measured at the individual level between time periods. The generated scores associated with each factor were subsequently used to classify each individual as shown in Table 4. Using this reclassification system for each factor, changes were measured between the periods in a qualitative scale and Table 5 shows that a significant change in attitudes occurred, and around $25 \%$ of respondents developed a changed perception, which justifies the consideration of the dynamic nature of travel perceptions, unlike the static nature in previous studies. 
Table 3: Pattern matrices generated from the factor analyses using the statements on travel attitudes and perceptions Statements/items

\begin{tabular}{rr}
\hline $\begin{array}{r}\text { Perception } \\
\text { about PT }\end{array}$ & $\begin{array}{r}\text { Sensitivity } \\
\text { environment } \\
\text { externalitie }\end{array}$ \\
.809 & .034 \\
.614 & .032 \\
.685 & -.017 \\
.444 & -.121 \\
.045 & .927 \\
.027 & .785 \\
.028 & .75 \\
-.107 & .514 \\
.018 & .043 \\
.011 & -.053 \\
.156 & .020 \\
-.064 & -.009 \\
\hline 26.89 & 14.15
\end{tabular}

Travelling by

Using public transport takes too much time

Public transport can sometimes be difficult than driving

People need to walk and cycle more to improve the environment

People need to walk and cycle more to reduce global warming

People need to use public transport more often to reduce traffic congestion

I need a car to do many of the things that I do

I could not manage pretty well without a car

Travelling by car is safer overall than taking public transport

Travelling by car is safer overall than walking

$\%$ of variance explained

Kaiser-Meyer-Olkin Measure of Sampling Adequacy.

Extraction Method

Rotation Method

Table 4: Labelling respondents according to their travel attitudes and perceptions

\begin{tabular}{lll}
\hline Factor & Classification of factor score & Labelled as \\
\hline Perception about PT & Positive score & Negative perception of PT \\
& Negative score & Positive perception of PT \\
\hline Sensitivity to environmental externalities & Positive score & Sensitive to environmental externalities \\
& Negative score & Insensitive to environmental externalities \\
\hline Car dependency & Positive score & Car dependent \\
& Negative score & Alternative mode seeker \\
\hline Safety of car travel & Positive score & Car safer \\
& Negative score & Car unsafe \\
\hline
\end{tabular}

2009

\begin{tabular}{|c|c|c|c|c|c|}
\hline $\begin{array}{r}\text { Car } \\
\text { dependency }\end{array}$ & $\begin{array}{r}\text { Safety of } \\
\text { car }\end{array}$ & $\begin{array}{r}\text { Perception } \\
\text { about PT }\end{array}$ & $\begin{array}{r}\text { Sensitivity to } \\
\text { environmental } \\
\text { externalities }\end{array}$ & $\begin{array}{r}\text { Car } \\
\text { dependency }\end{array}$ & $\begin{array}{r}\text { Safety of } \\
\text { car }\end{array}$ \\
\hline-.002 & -.075 & .803 & .032 & .003 & -.073 \\
\hline .107 & -.035 & .631 & -.017 & -.075 & .146 \\
\hline-.062 & .161 & .699 & .035 & .100 & -.037 \\
\hline .016 & .075 & .440 & -.116 & .031 & .074 \\
\hline-.027 & .041 & .048 & .926 & -.021 & .041 \\
\hline-.047 & .038 & .031 & .789 & -.047 & .037 \\
\hline-.011 & -.007 & .025 & .754 & -.011 & -.006 \\
\hline .059 & -.060 & -.111 & .510 & .058 & -.062 \\
\hline .810 & .012 & .013 & .045 & .806 & .014 \\
\hline .640 & .023 & .017 & -.053 & .634 & .022 \\
\hline .028 & .694 & .147 & .021 & .022 & .704 \\
\hline .022 & .665 & -.064 & -.008 & .024 & .658 \\
\hline \multirow[t]{5}{*}{7.10} & 4.41 & 26.13 & 14.70 & 7.06 & 4.17 \\
\hline & 52.55 & & & & 52.07 \\
\hline & 0.79 & & & & 0.79 \\
\hline & & & & Principal A & actoring \\
\hline & & & - & 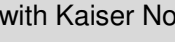 & zation \\
\hline
\end{tabular}


Table 5: Distribution of travel perceptions and their changes between 2009 and 2011

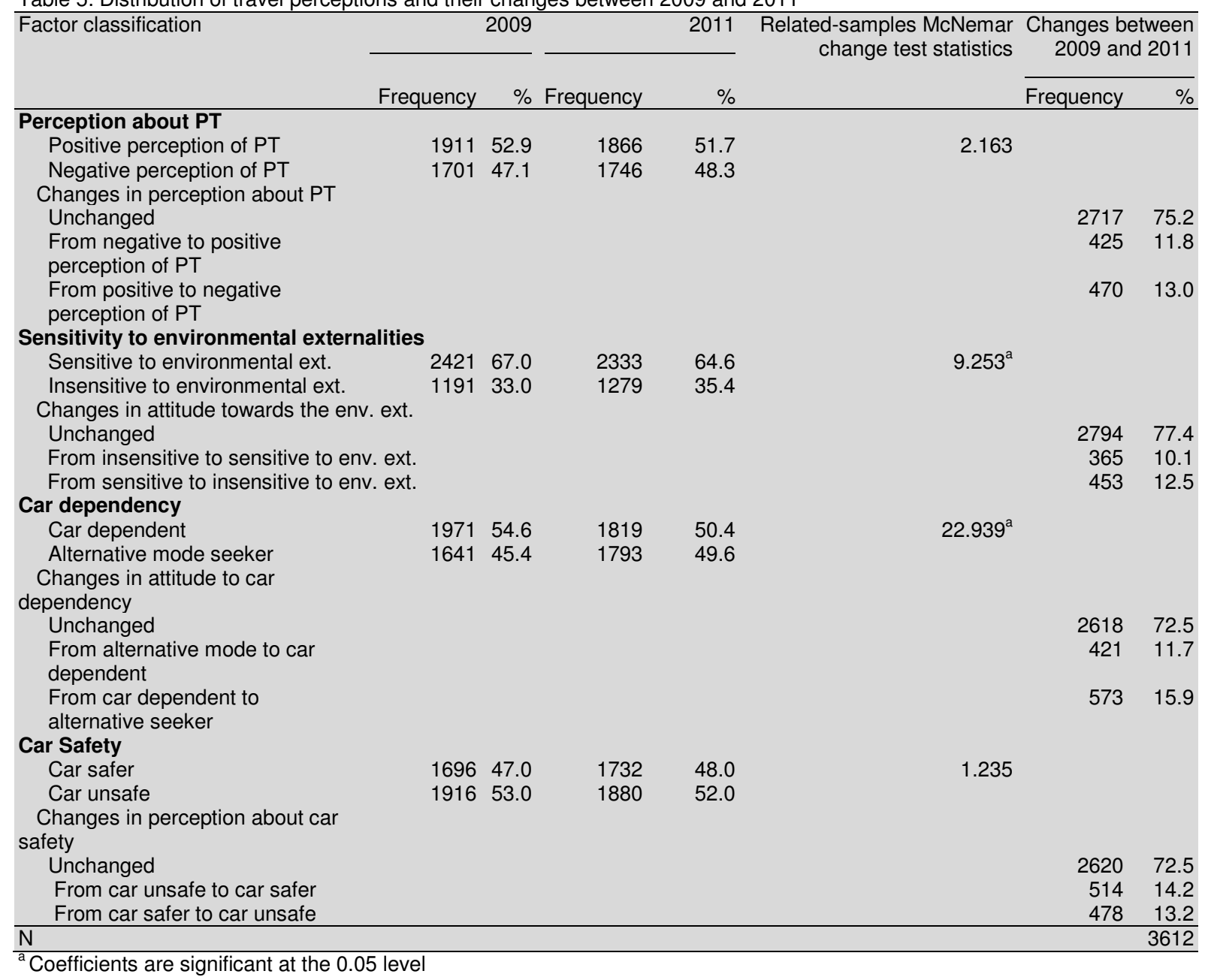

\subsubsection{Derivation of living preferences to control for residential self-selection effect}

In the HABITAT survey, participants were requested to specify the importance of 10 factors (statements) that influenced their decision to move into the current address. This was measured using a 5-point Likert scale (1 - not at all important to 5 - very important). A factor analysis was conducted using the scores associated with the scores of the 10 statements. Like the travel attitudes and preferences, this analysis was also conducted based on the principal axis factoring with oblique rotation method. A similar method has been used in the literature in order to take into account the self-selection effects (Kamruzzaman et al. 2014). Table 6 shows that the factor analysis generated a 4 factor solution: the strength of the statements associated with each of the factors suggests that the choice of a particular neighbourhood is due to its: a) accessibility and mobility options; b) natural environment; c) 
child centric facilities; and d) ease of access to work and city. The scores of the four factors were entered into the models in order to control for self-selection effects.

\begin{tabular}{lrrr} 
Table 6: Pattern matrix showing main reasons for choosing the current address as a place to live \\
\hline Items & $\begin{array}{r}\text { Accessibility and } \\
\text { mobility of places }\end{array}$ & $\begin{array}{r}\text { Natural } \\
\text { environment }\end{array}$ & $\begin{array}{r}\text { Child centric Conducive to travel } \\
\text { facilities }\end{array}$ \\
time saving
\end{tabular}

\subsection{Data analysis}

Two regression models were estimated to examine the relationship between urban form and walking duration: a) a zero inflated negative binomial regression model of time spent walking for transport in 2011 as the dependent variable--a cross-sectional analysis; and b) a multiple linear regression model incorporating changes in walking duration as the dependent variable - a longitudinal analysis. Both models were estimated in Stata. To account for the clustering effect of the sampling strategy adopted in this study, the vce (cluster clustvar) option was used to obtain a robust variance estimate that adjusted for the within-CCD cluster correlation (Greenwald 2006). The CCD code was used as the clustering variable in the model. Only statistically significant effects were retained in the final models.

\subsubsection{Zero-inflated negative binomial regression model for cross-sectional analysis}

Figure 3a outlines the distribution of reported 2011 walking time data are strongly skewed to the right and better approximated by a Poisson or negative binomial. In addition, the data contain a preponderance of zeroes, whereby 2295 individuals out of 3612 reported zero minutes of walking for transport. Although previous studies have applied multiple linear regression with a log transformation in this situation (Cao et al. 2007), such a transformation produces a bimodal distribution due to the large number of zeros. Given that the count of minutes walking is approximately Poisson distributed and the preponderance of zeroes in 
the data, a dual-state process requiring a zero-inflated model is appropriate (Washington et al. 2010). A dual state process arises when zeroes occur as a result of two separate but unobserved underlying causes—reported zeroes from individuals that essentially never engage in walking, and reported zeroes that arise from walkers that happened to not walk on the survey day. To test for equivalence of mean and variance in the walking data, both zero inflated Poisson (ZIP) and zero inflated negative binomial regression models (ZINB) are appropriate candidates.

a.

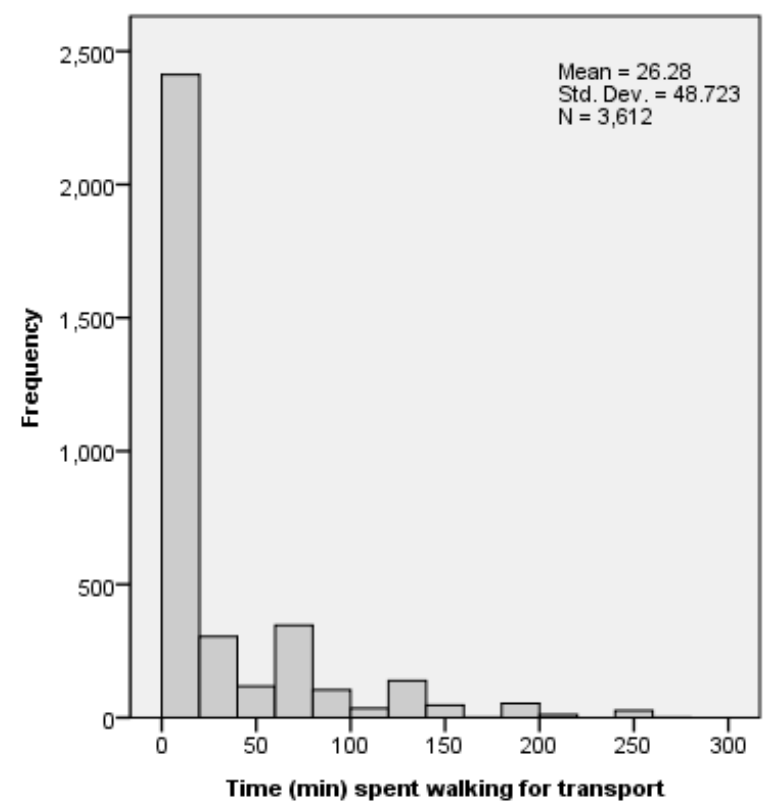

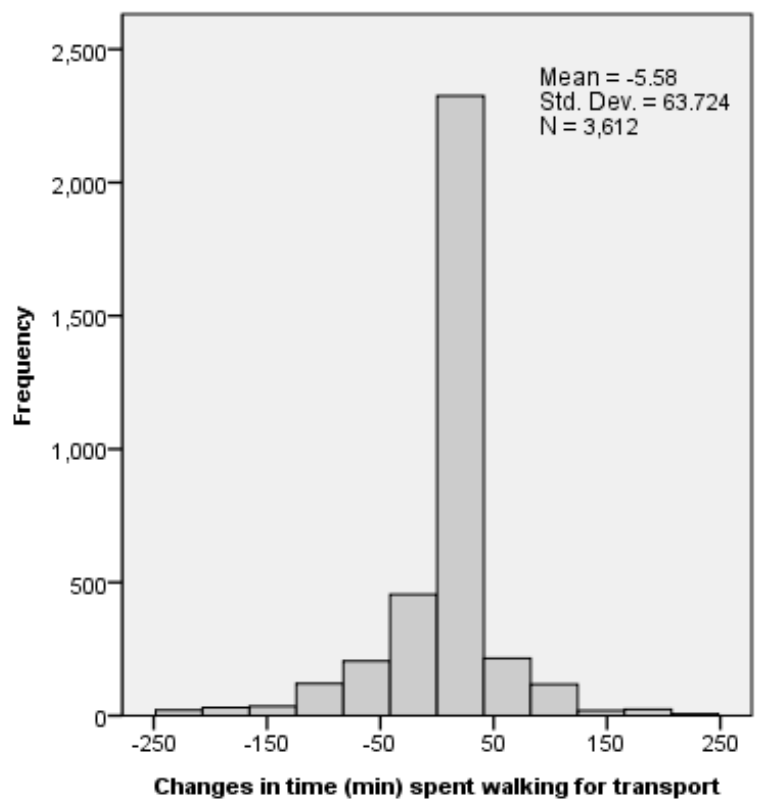

Figure 3: Distribution of continuous outcome variables

Washington et al. (2010) suggest that the best model should be chosen based on goodnessof-fit statistics amongst competing models along with plausibility and agreement with expectations. As a result, the 'countfit' command was run in Stata using all the explanatory variables included in order to compare the model residuals between negative binomial regression model (NBRM), ZINB, and ZIP regression. In addition, to test the appropriateness of fitting a zero-inflated model rather than a traditional model, the Vuong test was also conducted. The results showed that ZINB was preferred over both ZIP and NBRM. The ZINB regression simultaneously estimates two separate statistical models to distinguish between walkers and non-walkers (true zeroes); a logit model is estimated as a function of covariates 
that predict which walking state someone is likely to belong (walker or non-walker). For walkers, a negative binomial regression is estimate to predict walking duration (which could also be a zero). The ZINB model parameters are converted to incident rate ratios (IRRs) (walking minutes/week) to ease interpretation---giving the factor increase in the odds associated with a one unit increase in an explanatory variable (e.g. being female). In the logit model, for example, a beta coefficient of 0.5 associated with land use diversity factor for an individual indicates that the odds that an individual would be in the true zero group increases by a factor of $\exp (0.5)=1.65$, or the IRR is 1.65 .

\subsubsection{Linear multiple regression for longitudinal analysis}

Figure $3 \mathrm{~b}$ shows that the changes in walking time data are approximately normally distributed. As a result, a linear multiple regression analysis was conducted using the changes in walking level between 2009 and 2011 as the dependent variable. The explanatory variables entered in this model include changes in: socio-demographic status, travel attitudes and perceptions, and urban form variables. In addition, research has shown that individuals' changed behaviour is a function of not only changed circumstances but also related to their 'base' values including walking duration in the base year (Krizek 2003). As a result, base values associated with socio-demographics, travel attitudes and perceptions, and urban form variables in 2009 were also included in the model, in addition to time spent walking for transport in 2009. Moreover, respondents' living preference variables were also included in the model to control for self-selection effects.

\section{Results}

Analysis showed that individuals walked an average of 32 minutes per week in 2009 ( $n=$ 3612 ), which decreased by 6 minutes to an average of 26 minutes in 2011 ( $n=3612)-a$ decline of $18 \%$ over two years (about $9 \%$ in a year). However, the average is much higher when non-walkers are excluded from analysis - 80 and 72 min/week in 2009 and 2011 respectively. A lower level of walking may also be attributed to the relatively older age cohort in this sample and the consideration of only walking for transport, leaving the other two forms 
of walking (walking for recreation, and walking for exercise). However, the above trends are consistent with findings reported for samples with similar age cohort in other Australian cities. For example, Giles-Corti et al. (2013) found that respondents walked on average 26 minutes in a week for transport-related purposes in Perth which was reduced by 8.5 min/week after one year. Similarly, Shimura et al. (2012) have also reported a decline in walking for transport by $4.1 \mathrm{~min} /$ day in Adelaide over a four year period. Analysis also showed that walking levels decreased for almost all groups, except for those whose car availability declined between 2009 and 2011, and those who became more sensitive to selfreported environmental externalities, although the increase was very small.

\subsection{Findings from cross-sectional analysis}

Several factors were significantly associated with walking state and duration, as shown in Table 7. The top panel of Table 7 identifies variables that influenced walking duration, while the bottom identifies variables that influenced the probability of being a non-walker. The negative coefficients in the bottom half of the table indicate that some factors reduce the likelihood of being a non-walker whereas positive coefficients indicate increased likelihood of being a non-walker. In the upper half of the table, incident rate ratios (IRR) are reported for walking duration.

Individuals who resided in neighbourhoods with well-connected street networks were less likely to be a non-walker in 2011, after controlling for the effects of travel attitudes and perceptions, neighbourhood preferences, and socio-demographics (Table 7). Similarly, individuals with accessible train stations were less likely to be non-walkers. Table 7 also shows that their level of walking was significantly higher than those who lived in areas with a poorer access to train stations (NBRM model).

In addition to significant influences of the built environment, travel attitudes and perceptions also had important influences on walking behaviour. All perceptual and attitudinal factors significantly affected the likelihood of being a non-walker. Table 7 shows that individuals 
having a positive perception of PT or sensitivity to environmental issues were less likely to be a non-walker, whereas individuals who were dependent on the car and perceived the car as a safer mode of transport were more likely to be a non-walker. Car dependent individuals and individuals who perceived the car as safe mode for travel spent significantly less time walking for transport in 2011 (NBRM model).

Like the attitudinal factors, Table 7 shows that residential self-selection significantly affects walking behaviour. Individuals who chose a neighbourhood for accessibility and mobility options are less likely to be a non-walker. These are the places perceived to have more destinations (shops), good access to transport, and walking friendly environment (Table 6). Individuals who consciously chose a child centric neighbourhood were more likely to be a non-walker. Table 7 also shows that females and older aged persons are more likely to be non-walkers; higher educated and low car ownership people are less likely to be nonwalkers. People with lower car availability and full time working status walked significantly more than their counterparts. Larger sized household walked significantly less.

Table 7: Cross sectional association between built environment and walking for transport (Std. Err. adjusted for 200 clusters in CCD)

\begin{tabular}{|c|c|c|c|}
\hline Time spent walking for transport in a week in 2011 & IRR & $\mathrm{z}$ & $\mathrm{P}>\mathrm{Z}$ \\
\hline \multicolumn{4}{|l|}{ Negative Binomial Regression Model (NBRM) } \\
\hline Perceived access to train station within 10 minutes: yes (ref: no) & 1.095 & 1.86 & 0.064 \\
\hline Travel attitudes and perceptions: car dependent (ref: alternative mode seeker) & 0.882 & -2.89 & 0.004 \\
\hline Travel attitudes and perceptions: car unsafe (ref: car-safer) & 0.884 & -2.88 & 0.004 \\
\hline Age & 0.987 & -3.79 & 0.000 \\
\hline Car availability: yes, sometime (ref: yes, always) & 1.146 & 2.08 & 0.038 \\
\hline Car availability: no (ref: yes, always) & 1.204 & 2.05 & 0.041 \\
\hline Car availability: do not drive (ref: yes, always) & 1.297 & 2.31 & 0.021 \\
\hline Employment: full time (ref: non-working) & 1.279 & 6.51 & 0.000 \\
\hline Household size & 0.943 & -3.08 & 0.002 \\
\hline Inflate (logit) model: propensity to be non-walker & Coef. & & \\
\hline Network connectivity & -0.003 & -3.65 & 0.000 \\
\hline Perceived access to train station within 10 minutes: yes (ref: no) & -0.286 & -2.81 & 0.005 \\
\hline Travel attitudes and perceptions: positive perception of PT (ref: negative perception) & -0.427 & -4.72 & 0.000 \\
\hline Travel attitudes and perceptions: sensitive to env. ext. (ref: insensitive) & -0.237 & -2.87 & 0.004 \\
\hline Travel attitudes and perceptions: car dependent (ref: alternative mode seeker) & 0.450 & 5.83 & 0.000 \\
\hline Travel attitudes and perceptions: car unsafe (ref: car-safer) & 0.310 & 3.70 & 0.000 \\
\hline Self-selection: accessibility and mobility of places & -0.229 & -4.86 & 0.000 \\
\hline Self-selection: child-centric facilities & 0.139 & 2.64 & 0.008 \\
\hline Female (ref: male) & 0.255 & 3.57 & 0.000 \\
\hline Age & 0.029 & 5.79 & 0.000 \\
\hline Education: diploma/certificates (ref: up to year 12 ) & -0.193 & -2.36 & 0.019 \\
\hline Education: graduates (ref: up to year 12) & -0.723 & -8.48 & 0.000 \\
\hline Car availability: yes, sometime (ref: yes, always) & -1.080 & -6.13 & 0.000 \\
\hline Car availability: no (ref: yes, always) & -1.148 & -4.69 & 0.000 \\
\hline Car availability: do not drive (ref: yes, always) & -0.848 & -4.30 & 0.000 \\
\hline Constant & -0.351 & -1.05 & 0.292 \\
\hline Log pseudolikelihood & & & -8941.738 \\
\hline Wald $\mathrm{chi}^{2}$ & & & 113.61 \\
\hline Number of observation & & & 3612 \\
\hline Nonzero observation & & & 1317 \\
\hline
\end{tabular}




\subsection{Findings from the longitudinal assessment of walking for transport behaviour}

The results of the longitudinal analysis are presented in Table 8. The longitudinal model

explained about $56 \%$ of the total variance in the changes in duration of walking for transport.

Considering the research findings reported elsewhere, the explanatory power in this model is quite favourable but not uncommon (Nkurunziza et al. 2012). Krizek (2003, p.272) stated that "R-squared values in most studies rarely exceed 0.30 , suggesting that there remains a considerable amount we do not know about predicting travel behaviour using cross-sectional data, much less predicting changes in travel from one year to the next".

\begin{tabular}{|c|c|c|c|}
\hline Explanatory factors & Coef. & $\mathbf{t}$ & $P>t$ \\
\hline \multicolumn{4}{|l|}{ Urban form: change variables (09-11) } \\
\hline Changes in net residential density & 0.393 & 2.26 & 0.025 \\
\hline \multicolumn{4}{|l|}{ Urban form: Base variables (09) } \\
\hline Perceived access to train station within 10 minutes: yes (ref: no) & 8.232 & 4.27 & 0.000 \\
\hline Network connectivity (number of 3-way intersections) & 0.027 & 1.70 & 0.091 \\
\hline \multicolumn{4}{|l|}{ Travel attitudes and perceptions: change variables (09-11) } \\
\hline Developed a negative perception of PT & -7.511 & -3.39 & 0.001 \\
\hline Became insensitive to environmental externalities & -5.675 & -2.58 & 0.011 \\
\hline Became car dependent & -9.453 & -3.43 & 0.001 \\
\hline From car unsafe to car safer & -4.515 & -2.06 & 0.041 \\
\hline \multicolumn{4}{|l|}{ Travel attitudes and perceptions: base variables (09) } \\
\hline Positive perception of PT (ref: negative perception) & 4.660 & 2.83 & 0.005 \\
\hline Sensitive to environmental externalities (ref: insensitive) & 4.063 & 2.67 & 0.008 \\
\hline Car dependent (ref: alternative mode seeker) & -9.878 & -5.49 & 0.000 \\
\hline Car safer (ref: car unsafe) & -4.829 & -2.84 & 0.005 \\
\hline \multicolumn{4}{|l|}{ Socio-demographics: change variables $(09-11)$} \\
\hline Car availability: decreased (ref: unchanged) & 16.246 & 4.05 & 0.000 \\
\hline Working hour: decreased (ref: unchanged) & -7.682 & -3.54 & 0.001 \\
\hline Changes in household sizes & -3.096 & -2.70 & 0.008 \\
\hline \multicolumn{4}{|l|}{ Socio-demographics: base variables (09) } \\
\hline Age & -0.623 & -5.25 & 0.000 \\
\hline Female (ref: male) & -3.390 & -2.15 & 0.033 \\
\hline Part time working (ref: non-working & 3.679 & 1.96 & 0.051 \\
\hline Full time working (ref: non-working) & 6.340 & 3.53 & 0.001 \\
\hline Household size & -2.204 & -2.94 & 0.004 \\
\hline Graduate (ref: up to year 12 ) & 7.152 & 4.39 & 0.000 \\
\hline Walking for transport in 2009 & -0.721 & -34.41 & 0.000 \\
\hline Constant & 52.798 & 6.12 & 0.000 \\
\hline$F(21,199)$ & & & 62.48 \\
\hline R-squared & & & 0.561 \\
\hline & & & 3612 \\
\hline
\end{tabular}

The data presented in Table 8 provide additional evidence of a relationship between walking for transport and the built environment, based on the time-order criterion of causality. Table 8 shows that increasing density in a neighbourhood increased the level of walking between 2009 and 2011. Street connectivity was identified as having a significant association within the cross-sectional model (Table 7), and the longitudinal model confirms that walking levels increased between 2009 and 2011 for those individuals who lived in a neighbourhood with highly connected street networks. Table 8 also suggests that good access to trains in 2009 
had a significant impact on changes in walking for transport between 2009 and 2011, consistent with the cross-sectional model.

The importance of travel attitudes and perceptions to changes in walking duration is shown in Table 8. Based on the time-order criterion, the data show that a change in perception and attitude significantly influences changes in walking levels. This is particularly true for those individuals who: a) developed negative perceptions about PT, b) became insensitive to environmental externalities, c) became car dependent, and d) developed stronger feelings that the car is a safer mode of transport. However, improved perceptions in these factors were not associated with changes in walking duration.

\section{Discussion and conclusions}

The global resurgence of and interest in compact urban development and healthy cities planning has increased the need to understand the relationships between urban design and active transport (OECD 2012). Most major cities in North America and Europe have embraced some aspect of this concept by implementing planning policies and development strategies with the intent of encouraging active transport. Important questions have been raised in the literature about the role of travel attitudes and perceptions in terms of residential self-selection effects, the adequacy of study designs, and omitted variable bias in identifying 'spurious' rather than causal linkages between the built environment and walking duration. The purpose of this study is to address many of the study design shortcomings identified in a rich literature on this topic, and to examine self-selection in the Australian context. The Brisbane-based HABITAT data set is a unique source of data with potential to be used in a 'natural' intervention study for rigorous examination (both cross-sectional and longitudinal) of relationships between the built environment, perceptual and attitudinal, and socio-demographic factors, with walking duration. In this research, both cross-sectional and panel assessment methods confirmed that the built environment influences walking participation, but that consideration of perceptual and attitudinal factors is also important for understanding these relationships. With the intent to test the relationship both spatially 
(cross sectional) and temporally (panel), common findings emerged, painting a consistent picture of the positive effects of the built environment on walking duration. A dual-state model was proposed to explain and understand differences between regular walkers and non-walkers, and revealed that built environment factors help to predict the likelihood of someone being a non-walker.

The research set out to assess the notion of causality of the built environment in influencing walking behaviour. The cross-sectional analysis confirmed the association of key environmental factors adjusting for travel attitudes and perceptions, residential self-selection, and socio-demographics (Table 9). Testing for the temporal nature of the relationships, the prospective model showed that significant changes in built environmental factors such as residential density have the potential to change walking behaviour.

Table 9: Summary of findings

\begin{tabular}{lll}
\hline Neighbourhood with & Cross-sectional findings & Longitudinal findings \\
\hline Well-connected street networks & Individuals less likely to be non-walker & Individuals' level of walking increases over time \\
\hline Increasing residential density & & Individuals' level of walking increases over time \\
\hline Accessible (perceived) train station & $\begin{array}{l}\text { Individuals less likely to be non-walker } \\
\text { Individuals walk significantly more }\end{array}$ & Individuals' level of walking increases over time \\
\hline
\end{tabular}

We conclude that changes to the built environment influence walking. Creating neighbourhoods with increased connectivity, increased density and easy access to PT is likely to increase transport walking. However, the importance of travel attitudes and perceptions needs to be understood and integrated. Findings of this research show that a positive perceptual and attitudinal change was not associated with increased walking for transport; however, a shift towards a less favourable attitude to walking was associated with a reduced propensity to walk. Therefore, consistent with the notion that both 'people' and 'places' are important (Ewing and Cervero 2010; Giles-Corti 2006), there is also a need to promote active travel. New opportunities for walking for transport, e.g., new destinations, new walking infrastructure, or more convenient access to transport, are likely to attract and entice walking, especially if their introduction is accompanied by awareness raising and 
attitudinal change strategies. This should be part of any built environment policy consideration.

Both cross-sectional and longitudinal analyses have consistently concluded that built environment factors influence walking for transport, but also highlight the role and importance of attitudes and perceptions in active transport decision making. Similar to Mokhtarian and Cao (2008), we argue against a "one or the other" explanation of walking duration, and instead suggest that attitude and built environment are inter-connected. This synergy should form the focus of future studies as well as planning policy interventions. In this study perceived changes in access to PT were not found to have a significant effect on walking for transport. Further research should include objective measures of access to PT and further investigate the results presented in this research. In addition, research should take into account longer-term effects that would better capture the built environment changes. A major challenge for research of this type is to better understand the causal mechanisms through which the built environment influences individual and community attitudes and social norms. This is a limitation of the current analyses and should be addressed in future studies.

\section{References}

Aditjandra P T, Cao X, Mulley C (2012) Understanding neighbourhood design impact on travel behaviour: An application of structural equations model to a British metropolitan data. Transportation Research Part A 46: 22-32.

Bagley M, Mokhtarian P (2002) The impact of residential neighborhood type on travel behavior: a structural equations modeling approach. Ann of Regional Sci 36: 279-297. Bhat C, Guo J (2007) A comprehensive analysis of built environment characteristics on household residential choice and auto ownership levels. Transport Res B 41: 506-526. Boarnet M G, Sarmiento S (1998) Can land use policy really affect travel behaviour? A study of the link between non-work travel and land-use characteristics. Urban Studies 35: 11551169. 
Brisbane City Council (2005) Brisbane Active Transport Strategy: Walking and Cycling Plan 2005-2010, Brisbane.

Brisbane City Council (2008) Transport Plan for Brisbane 2008 - 2026, Brisbane.

Cao X, Mokhtarian P L, Handy S L (2007) Do changes in neighborhood characteristics lead to changes in travel behavior? A structural equations modeling approach. Transportation 34: 535-556.

Cerin E, Leslie E, Owen N (2009) Explaining socio-economic status differences in walking for transport: An ecological analysis of individual, social and environmental factors. Social Science and Medicine 68: 1013-1020.

Cervero R, Duncan M (2008) Residential self-selection and rail commuting: a nested logit analysis. University of California Transportation Center.

Cools M, Moons E, Janssens B, Wets G (2009) Shifting towards environment-friendly modes: profiling travelers using Q-methodology. Transportation 36: 437-453.

Craig C L, Marshall A L, Sjostrom M, Bauman A E, Booth M L, Ainsworth B E, Pratt M, Ekelund U, Yngve A, Sallis J F, Oja P (2003) International physical activity questionnaire: 12-country reliability and validity. Med sci sports exerc 35: 1381-1395.

De Vos J, Derudder B, Van Acker V, Witlox F (2012) Reducing car use: changing attitudes or relocating? The influence of residential dissonance on travel behavior. Journal of Transport Geography 22: 1-9.

Duncan M J, Winkler E, Sugiyama T, Cerin E, duToit L, Leslie E, Owen N (2010) Relationships of Land Use Mix with Walking for Transport: Do Land Uses and Geographical Scale Matter? Journal of Urban Health 87 782-795.

Elias W, Shiftan Y (2012) The influence of individual's risk perception and attitudes on travel behavior. Transportation Research Part A 46: 1241-1251.

Ewing R, Cervero R (2010) Travel and the Built Environment. JAPA 76: 265-294.

Frank L D, Schmid T L, Sallis J F, Chapman J, Saelens B E (2005) Linking objectively measured physical activity with objectively measured urban form: Findings from SMARTRAQ. American Journal of Preventive Medicine 28: 117-125. 
Giles-Corti B (2006) People or places: What should be the target? Journal of Science and Medicine in Sport 9: 357-366.

Giles-Corti B, Bull F, Knuiman M, McCormack G, Van Niel K, Timperio A, Christian H, Foster S, Divitini M, Middleton N, Boruff B (2013) The influence of urban design on neighbourhood walking following residential relocation: Longitudinal results from the RESIDE study. Social Science \& Medicine 77: 20-30.

Greenwald M, Boarnet M (2001) The built environment as a determinant of walking behavior: analyzing non-work pedestrian travel in Portland, Oregon. Transportation Research Record 1780: 33-42.

Greenwald M J (2006) The relationship between land use and intrazonal trip making behaviors: Evidence and implications. Transportation Research Part D 11: 432-446. Guo J Y, Chen C (2007) The built environment and travel behavior: making the connection. Transportation 34: 529-533.

Guo Z (2009) Does the pedestrian environment affect the utility of walking? A case of path choice in downtown Boston. Transportation Research Part D 14: 343-352.

Handy S, Cao X, Mokhtarian P (2005) Correlation or causality between the built environment and travel behavior? Evidence from Northern California. Transportation Research Part D 10: 427-444.

Handy S, Cao X, Mokhtarian P (2006) Self-selection in the relationship between the built environment and walking - Empirical evidence from northern California. JAPA 72: 55-74. Handy S, Clifton K (2001) Local shopping as a strategy for reducing automobile travel. Transportation 28: 317-346.

Humpel N, Owen N, Iverson D, Leslie E, Bauman A (2004) Perceived environment attributes, residential location, and walking for particular purposes. American Journal of Preventive Medicine 26: 119-125.

Kamruzzaman M, Baker D, Washington S, Turrell G (2013a) Residential dissonance and mode choice. Journal of Transport Geography 33: 12-28. 
Kamruzzaman M, Baker D, Washington S, Turrell G (2014) Advance transit oriented development typology: Case study in Brisbane, Australia. Journal of Transport Geography 34: 54-70.

Kamruzzaman M, Hine J (2011) Participation index: a measure to identify rural transport disadvantage? Journal of Transport Geography 19: 882-899.

Kamruzzaman M, Washington S, Baker D, Turrell G (2013b) Does residential dissonance affect residential mobility? Transportation Research Record 2344: 59-67.

Khattak A J, Rodriguez D (2005) Travel behavior in neo-traditional neighborhood developments: a case study in USA. Transportation Research Part A 39: 481-500.

Krizek K J (2003) Residential relocation and changes in urban travel: Does neighborhoodscale urban form matter? JAPA 69: 265-281.

Krizek K J, Handy S L, Forsyth A (2009) Explaining changes in walking and bicycling behavior: challenges for transportation research. Environment and Planning B 36: 725-740. Lee C, Moudon A V (2006) The 3Ds+R: Quantifying land use and urban form correlates of walking. Transportation Research Part D 11: 204-215.

Lee I M, Ewing R, Sesso H D (2009) The Built Environment and Physical Activity Levels: The Harvard Alumni Health Study. American Journal of Preventive Medicine 37: 293-298. Leslie E, Coffee N, Frank L, Owen N, Bauman A, Hugo G (2007a) Walkability of local communities: using geographical information systems to objectively assess relevant environmental attributes. Health and Place 13: 111-122.

Leslie E, McCrea R, Cerin E, Stimson R (2007b) Regional Variations in Walking for Different Purposes: The South East Queensland Quality of Life Study. Environ Behav 39: 557-577. Leslie E, Saelens B, Frank L, Owen N, Bauman A, Coffee N, Hugo G (2005) Residents' perceptions of walkability attributes in objectively different neighbourhoods: a pilot study. Health and Place 11: 227-236.

Manaugh K, El-Geneidy A M (2013) Does distance matter? Exploring the links among values, motivations, home location, and satisfaction in walking trips. Transportation Research Part A 50: 198-208. 
Matthies E, Kuhn S, Klöckner C A (2002) Travel Mode Choice of Women: The Result of Limitation, Ecological Norm, or Weak Habit? Environ Behav 34: 163-177.

Meurs H, Haaijer R (2001) Spatial structure and mobility. Transportation Research Part D 6: 429-446.

Mokhtarian P L, Cao X (2008) Examining the impacts of residential self-selection on travel behavior: A focus on methodologies. Transportation Research Part B 42: 204-228. Nkurunziza A, Zuidgeest M, MarkBrussel, Maarseveen M V (2012) Examining the potential for modal change: Motivators and barriers for bicycle commuting in Dar-es-Salaam. Transport Policy 24: 249-259.

Oakes J M, Forsyth A, Schmitz K H (2007) The effects of neighborhood density and street connectivity on walking behavior: the Twin Cities walking study. Epidemiologic Perspectives \& Innovations 4 .

OECD (2012) Compact City Policies: A Comparative Assessment. OECD publishing. Pinjari A, Pendyala R, Bhat C, Waddell P (2007) Modeling residential sorting effects to understand the impact of the built environment on commute mode choice. Transportation 34: 557-573.

Queensland Government (2008) Toward Q2: Tomorrow's Queensland, Brisbane.

Queensland Government (2009a) Action Plan for Walking 2008-2010, Brisbane.

Queensland Government (2009b) South East Queensland Regional Plan 2009-2031. Brisbane.

Ramon M-R (2010) Walking accessibility to bus rapid transit: Does it affect property values? The case of Bogotá, Colombia. Transport Policy 17: 72-84.

Saelens B, Sallis J, Frank L (2003) Environmental correlates of walking and cycling: Findings from the transportation, urban design, and planning literatures. Annals of Behavioral Medicine 25: 80-91.

Salon D (2009) Neighborhoods, cars, and commuting in New York City: A discrete choice approach. Transportation Research Part A 43: 180-196. 
Schwanen T, Mokhtarian P (2005a) What affects commute mode choice: neighbourhood physical structure or preferences toward neighborhoods? J of Trans Geog 13 83-99.

Schwanen T, Mokhtarian P (2005b) What if you live in the wrong neighborhood? The impact of residential neighborhood type dissonance on distance traveled. Transportation Research Part D 10: 127-151.

Shimura H, Sugiyama T, Winkler E, Owen N (2012) High neighborhood walkability mitigates declines in middle-to-older aged adults' walking for transport. Journal of Physical Activity and Health 9: 1004-1008.

Singleton R A, Straits B C (1999) Approaches to Social Research. Oxford University Pres, New York and Oxford.

Smith P N, Taylor C J (1994) A method for the rationalisation of a suburban railway network. Transportation Research Part A: Policy and Practice 28: 93-107.

Stangl P, Guinn J M (2011) Neighborhood design, connectivity assessment and obstruction. Urban Design International 16: 285-296.

Thøgersen J (2006) Understanding repetitive travel mode choices in a stable context: A panel study approach. Transportation Research Part A 40: 621-638.

Transportation Research Board (2005) Does the built environment influence physical activity? Examining the evidence. TRB Special Report 282, Washington, DC.

UCLA: Academic Technology Services (2012) Stata FAQ: How can I use countfit in choosing a count model? Statistical Consulting Group.

Van Cauwenberg J, De Bourdeaudhuij I, De Meester F, Van Dyck D, Salmon J, Clarys P, Deforche B (2011) Relationship between the physical environment and physical activity in older adults: A systematic review. Health \&amp; Place 17: 458-469.

Vance C, Hedel R (2007) The impact of urban form on automobile travel: disentangling causation from correlation. Transportation 34: 575-588.

Washington S, Matthew K, Mannering F (2010) Statistical and Econometric Methods for Transportation Data Analysis. Chapman \& Hall/CRC, Boca Raton. 